\title{
Theoretical Basis of Allometric Relationships in Juvenile Brachyura: Data from a West African Mangrove Swamp Crab Population
}

\author{
I. Ewa-oboho and N. J. Abby-kalio* \\ Institute of Oceanography, University of Calabar, P. M. B. 1115, Calabar, Nigeria \\ * Marine Biology Unit, Department of Biology, University of Science \& Technology, Port \\ Harcourt, Nigeria
}

\begin{abstract}
The carapace length-weight relationship in juvenile Brachyura (crabs) was studied theoretically to assess the relevance of the allometric factor and the validity of the condition factor as these factors are often not determined because most fishery investigations are conducted for adult population. The allometric factor appears to be the main parameter in the equation: $\mathrm{W}=\mathrm{aL}^{\mathrm{b}}$ (where $\mathrm{W}=$ weight, $\mathrm{a}$ is a constant and $\mathrm{L}=$ carapace length). Parameters a (also called the condition factor $\mathrm{K}$, known as the ponderal index) and $\mathrm{k}=10^{3} \mathrm{~W} / \mathrm{L}^{3}$ were found to be of less significance and they were closely related to $b$. The theoretical value of $b=3$ was found to be rarely met in crab fishery studies; rather much wider range was observed. It was, therefore, recommended that the assumed theoretical value of $b=3$ would not be applied in all ichthiofauna surveys as it is generally commonly done by fishery scientists. The present analytical studies has opened a new approach to the elucidation of the biological significance of the allometric factor $b$, through the theories of tractal geometry (where $\mathrm{b}$ is seen as a fractal dimension equivalent and salutatory ontogeny where $\mathrm{b}$ is a critical point in the early life history of crabs.
\end{abstract}

\section{Introduction}

The early development of Brachyura is characterized by several distinct stages of growth during which rapid physiological and structural changes occur. Growth is by ecdysis, resulting in distinct "Stanza" which are separated by the presence of morphological changes or by sudden change in growth rate (Abby-kalio \& Warner, 1984; Cott, 1929; Davidson \& Marsdon, 1987; Huxley, 1932; Lee. 1992; Harcourt, 1978; Safran, 1992). It has been observed that length varies in relation to weight within a distinct stage of development (Safran, 1992). Ricker (1980) emphasized the necessity for obtaining fauna in a wide size range when a general length-weight relationship for a population is required.

Most brachyuran surveys are focused on large adults and, thus, the growth parameters of length and weight are described only for adult individuals of the various species. Estimated parameters, when only adult specimens are used, can deviate enormously from their actual values. Based on the large number of juvenile crabs collected during a 3-year (1986-1988) field study of crab ecology in the Bonny estuary, the present investigation assesses the value of allometric factors connecting length and weight and re-evaluates the validity of the condition factor which is widely applied in ichthyological researches. This paper presents an analytical concept of the length-weight relationship in crab juveniles based on the fractal (Mandelbrot, 1984; Frontier, 1987) and saltatory ontogeny (Balon, 1984) theories.

\section{Materials and methods}

Different species of crab juveniles were caught during a nursery ecosystem survey along the Bonny-Port Harcourt estuarine system during 1986-1988 (Ewa-oboho,1988; 1993). Crab specimens were preserved in a $40 \%$ solution of buffered formalin and stored for later sorting, identification and analyses. Carapace width was measured to the nearest millimeter while the weight of each species was determined to the nearest gram. Analyses of stomach content were also carried out. A formulation of the length-weight relationship generally applicable to many 
species and body forms was introduced by Le Cren (1951). In most aquatic forms this relationship may be expressed by the formula:

$\mathrm{W}=\mathrm{aL}^{\mathrm{b}}$, where $\mathrm{W}=$ weight, $\mathrm{L}=$ Length (or carapace width $(\mathrm{CW})$ in crabs).

a is a constant (the condition factor, so called because it indicates the physiological condition of the studied fauna relative to a specific standard), and b is the allometric factor. This relationship can also be expressed as:

$$
\log W=\log a+b \log L(C W)
$$

In which case the weight-length data for crab of the same weight VS carapace width relationship will fall roughly on a straight line if plotted on a log - log paper (Weatherley, 1972).

Since an individual crab cannot be measured and weighed in successive years of its life, this expression cannot be applied at its best. Rather, the value of $b$ is determined by plotting the logarithm of length against the logarithm of weight for a large number of crabs of various sizes, the gradient of the fitted line is estimated as b (Ricker, 1980) and passes through the average point o of many points, with $\log \mathrm{CW}$ and $\log \mathrm{W}$ as co-ordinates, $\mathrm{b}=6 \log \mathrm{W} / \log \mathrm{CW}$, and $\log \mathrm{a}$ as the origin co-ordinate. Parameters $b$ and a are characteristics of the species within the study period (interval) when the cluster of points is rectilinear.

Since the interval in juveniles is usually small and the mean point fixer the condition factor, a becomes a very critical parameter for fitting the allometric line and $\log$ a inversely proportional to allometric factor b (Fig. 1).

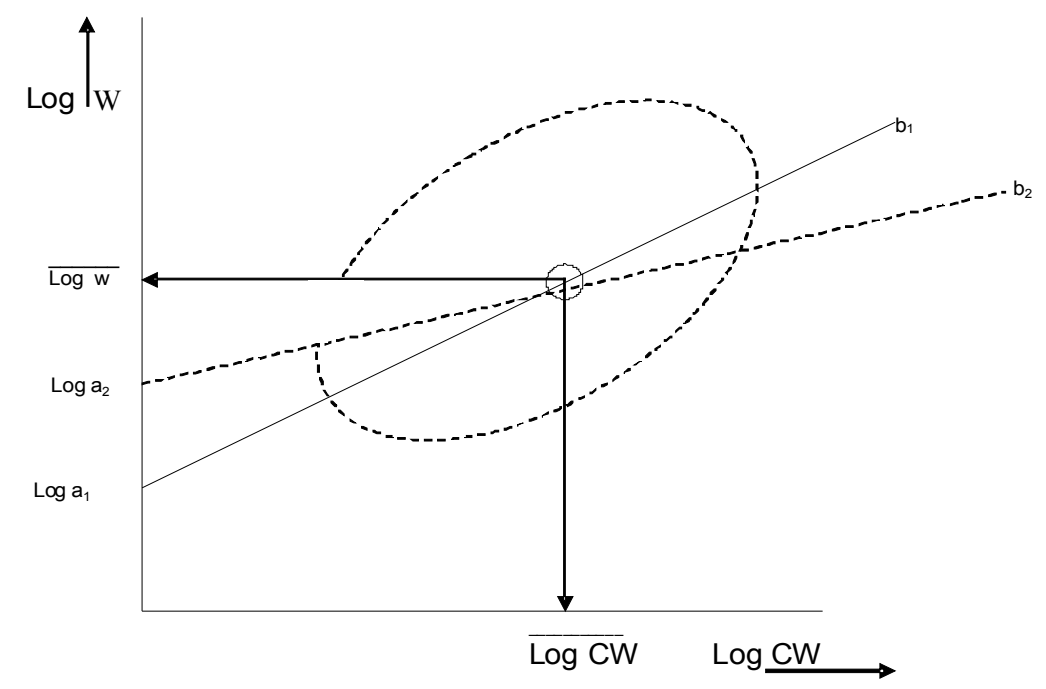

Fig. 1. Length (carapace width, CW) - weight relationship, showing the relation between $\log w \operatorname{and} \log \mathrm{CW}$ with the values of $b$ variable. W: weight; $C W$ : carapace width; $a$ : condition factor; $b$ : allometric factor: 0 : mean point, point of clustered points.

The instantaneous allometric factor $\mathrm{b}$ was deduced for a given population of crabs from $\mathrm{a}$ calculation of the gradient of the fitted line obtained in each sample. To obtain the allometric factor for a typical crab population, two procedures were applied. Firstly, a mean b value was deduced from all instantaneous $b_{i}$ values $\Sigma^{\mathrm{N}} b_{i} n$ called the average allometric 
factor. Secondly, there was superimposition of all graphic representations to yield a straight line, with gradient $b$ which is the general allometric factor. Mean allometric factors $b$ were due to instanta-neous distributions, which explained the difference between their values and those of the general allometric factor b (Fig. 2).

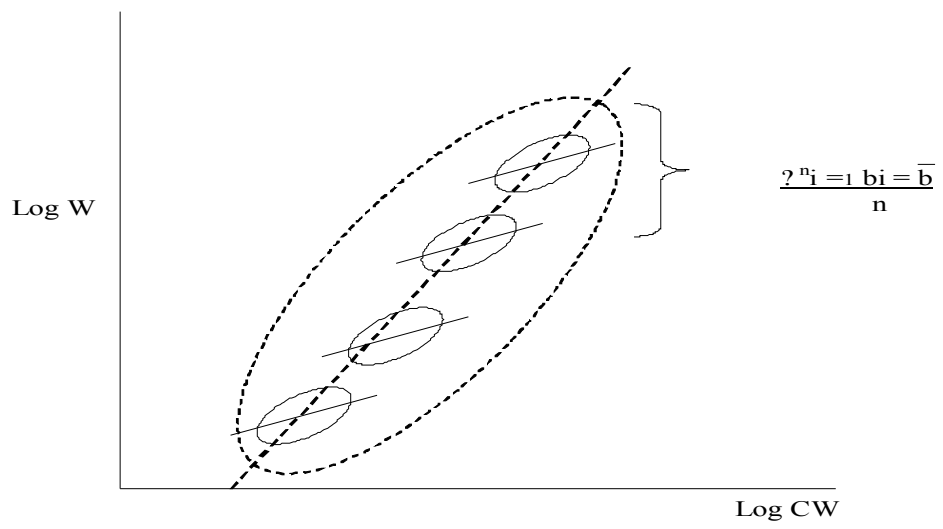

Fig. 2. The carapace width $(C W)$ crab - weight $(W)$ relationship, showing many instantaneous slopes $b_{i}($ with a mean value of $\mathbf{b}=\Sigma^{\mathbf{n}}{ }_{\mathbf{i}}=\mathbf{b}_{\mathbf{i}} / \mathbf{n}$ and a general slope $\mathbf{b}$. $\mathrm{i}=1$

The least squares regression value $b=3$ describes isometric growth, which would characterize a crab of unchanging body form provided its specific gravity remains unchanged. Nevertheless, some variability -either seasonal or individual - remains, due to time, stomach contents, spawning conditions, etc. On the other hand, some species have b values characteristically greater or less than 3, a condition described as isometric growth. When $\mathrm{b}<3, \mathrm{CW}^{\mathrm{b}}$ increases faster than $\mathrm{W}$ (weight and, therefore, volume): the shape of the animal tends towards flatness when carapace width increases. When $b>3$, the crab becomes more spherical with increased carapace width.

Carapace width and weight for a particular sample or individual were compared using Fulton's (1911) condition factor $(\mathrm{K}), \mathrm{K}=\mathrm{W} / \mathrm{L}^{3}$ or $\mathrm{W} / \mathrm{CW}^{3}$. This represents the parameter a in the allometric equation, with an assumed value of $b=3$. The heavier a crab is for a given carapace width, the greater the condition factor, and, by implication, the better the condition. Fulton's factor is nevertheless difficult to apply and Bauchot \& Banchot (1978) proposed a more universal formula:

$$
\mathrm{K}=1000 \mathrm{~W} / \mathrm{L}^{3}
$$

$\mathrm{K}$ is called the ponderal index, since it can be applied to a wide range of species and allows numerical comparison to be made more easily. It represents the somatic weight in grams for a crab $10 \mathrm{~cm}$ in width of carapace. Using the stomach con-tents index (SCI) some growth comparisons were made $(\mathrm{SCI}=$ weight of total stomach contents $) \times 10^{2} /$ (total $\mathrm{crab}$ weight) (Hyslop, 1980).

\section{Results}

Within species relationship were determined for pairs of $\mathrm{CW}-\mathrm{W}$ values in juvenile-stage fiddler crabs (Uca tangeri Linnaeus), ranging in carapace width $(\mathrm{CW})$ from 15 to $65 \mathrm{~mm}$. The correlation coefficient $r=0.987$ was greatest with the following equations, which fitted 335 pairs of values (with $\mathrm{x}=\log \mathrm{CW}$ and $\mathrm{Y}=\log \mathrm{W}$ ): 


$$
\begin{aligned}
& \mathrm{Y}=4.182 \mathrm{x}-3.082 ; \\
& \mathrm{Y}=0.264 \mathrm{x}^{2}+2.250 \mathrm{x}-1.462 ; \\
& \mathrm{Y}=0.564 \mathrm{x}^{3}-126 \mathrm{x}^{2}+3.835 \mathrm{x}-2.256
\end{aligned}
$$

The correlations of the quadratic fitting curve and the linear regression curve were almost equal. The cubic fitting curve was adjusted for irregularities in the small sized crab juveniles. Fig. 3 shows the graphical representation of the relationship between width and crap weight in dual logarithmic coordinates fitted by 401 pairs of values to obtain the following equation:

$\mathrm{Y}=3.0202 \mathrm{x}+1.0324$

with $\quad r=0.995$

In Fig. 4, 182 pairs of values from samples collected yields the general equation

$$
\mathrm{y}=3.092 \mathrm{x}-1.981(r=0.998) \text { is illustrated. }
$$

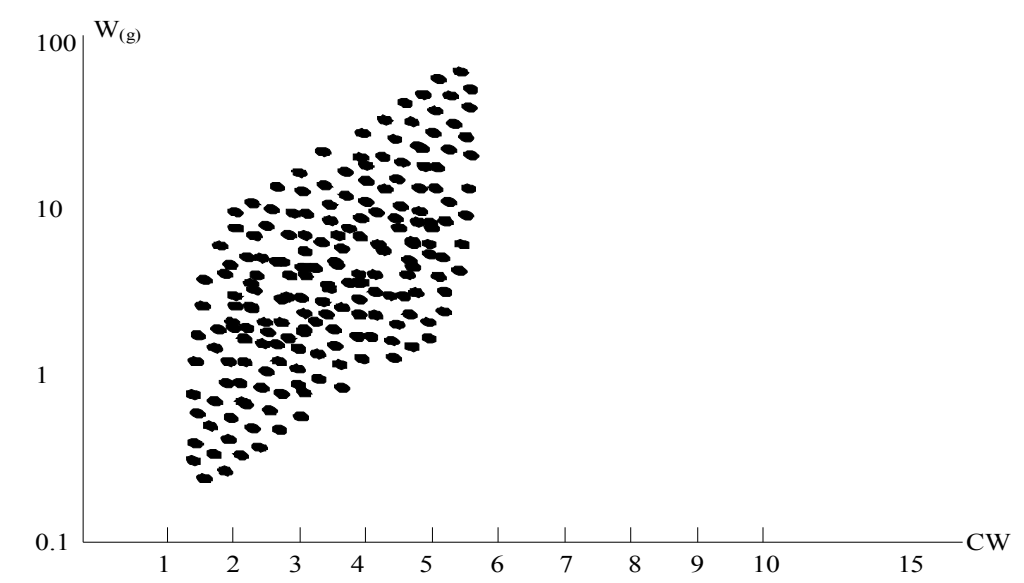

Fig. 3. Uca tangeri carapace width weight relationship in fiddler crab juveniles. The log - log diagram is fitted by 401 pairs of values $\left(\mathrm{W}=7.56 \times 10^{-3} \mathrm{CW}^{3.058}, r=0.995\right)$

This revealed two groups: 32 pairs of values from one sample represented a group for which $\mathrm{Y}=$ $2.892 \mathrm{x}-1.926(r=0.985)$, and 150 pairs of values from another sample represented a group for which $\mathrm{y}=2.989 \mathrm{x}-1.899(r=0.958)$.

Growth comparison was also made in addition to the above analysis (Fig. 4) using stomach content weight (SW) vs body weight (W), where 165 pairs of values led to the general equation $\mathrm{SW}=0.112 \mathrm{~W}-0.0168$, revealing the same obvious groups $(r=0.964)$, 62 pairs of values represented a group for which $\mathrm{SW}=0.102 \mathrm{~W}+0.167(r=0.942)$ and 96 pairs of values represented a group for which $\mathrm{SW}=0.0871 \mathrm{~W}-0.004(r=0.902)$. No relationship existed between the SCI and body weight of crabs. 


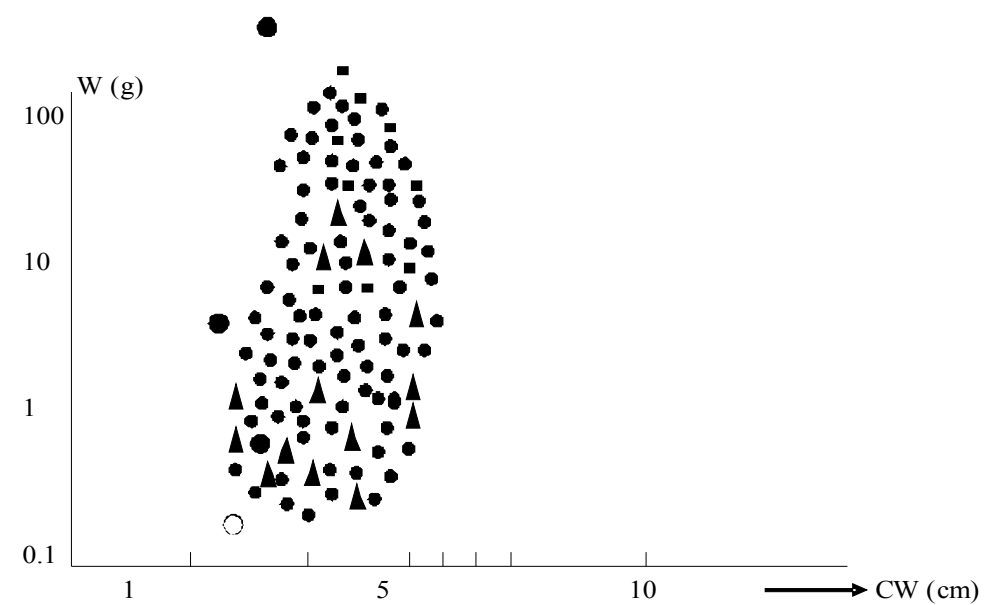

Fig. 4. Uca tangeri weight-carapace width (W-CW) relationship plotted on a log-log diagram, fitted by 182 pairs of values $\left(\because \mathrm{W}=8.63 \times 10^{-3} \mathrm{CW}^{3092}, r=0.998\right) ; \quad: 32$ pairs of values composing Group $\mathrm{A} . \mathrm{W}=18.26 \times$ $\left.10^{-3} \mathrm{CW}^{2.892}, r=0.985\right) ; \quad: 150$ pairs of values composing Group $\mathrm{B}$. $\left(\mathrm{W}=12.66 \times 10^{-3} \mathrm{CW}^{2.989}, r=0.958\right)$

Table 1 gives the analysis of instan-taneous sample parameters with the following ranges: $0.910 \leq r \leq 0.988$, and $2.361 \leq \mathrm{b} \leq 3.486$, with $\mathrm{b}=2$. Parameters $\mathrm{a}$ and $\mathrm{b}$ were found to be related with a correlation coefficient $r=-0.964$, a was dependent on $\mathrm{b}$, thus:

$$
\begin{aligned}
& a=-0.0182 b+0.0665 \\
& a=0.0116 b^{2}-0.0547 b+0.163 \\
& a=0.0202 b^{3}-0.552 b^{2}+0.890 b-0.676
\end{aligned}
$$

Uca tangeri seems, therefore, to maintain its general shape (oval) as the allometric factor, which compares volume to width tended towards isometric condition.

Table 2 presents a similar analysis of crab juvenile from a coastal nursery along Escravos (western Nigeria delta) with the following ranges:

$2.42($ Padmgrapsusgracils $) \leq \mathrm{bi}=4.16$

(Achacus powelli)

2.65 (Ocypode cursor) $\leq \mathrm{b} \leq 3.28$

(Sesarma huzardi)

2.65 (Goniopsis pelii) $\leq \mathrm{b} \leq 3.01$

(Panopeus africana)

TABLE 1

Variability of instantaneous growth parameters in the carapace width-weight relationship in juveniles. Sn: sample number, Ni: number of individual in sample, $r$ : correlation coefficient; $a$ : condition factor, $b$ : allometric factor, $C W$ : mean carapace width (cm) and $W$ : mean crab weight $(g)$

$\begin{array}{rrrrrrrrl}S n & N i & \mathrm{r} & A\left({ }^{\prime} 10^{-2}\right) & b & C W & S D & W & S D \\ & & & & & & & & \\ \text { 1. } & 401 & 0.995 & 0.92 & 3.058 & 4.18 & 1.22 & 2.361 & 2.628 \\ \text { 2. } & 38 & 0.997 & 0.96 & 3.008 & 4.26 & 1.27 & 2.886 & 2.211 \\ \text { 3. } & 192 & 0.995 & 1.38 & 2.826 & 3.19 & 1.24 & 1.862 & 1.851 \\ \text { 4. } & 12 & 0.994 & 1.08 & 2.995 & 3.86 & 1.22 & 1.896 & 2.614 \\ 5 . & 260 & 0.926 & 1.05 & 2.989 & 4.11 & 1.31 & 2.188 & 2.0 \\ 6 . & 233 & 0.921 & 1.01 & 3.012 & 3.46 & 1.281 & 2.626 & 2.2 \\ \text { 7. } & 82 & 0.992 & 1.39 & 2.836 & 3.28 & 1.26 & 1.145 & 1.99 \\ \text { 8. } & 46 & 0.994 & 0.95 & 3.12 & 2.89 & 1.21 & 1.81 & 2.4 \\ \text { 9. } & 294 & 0.996 & 1.28 & 2.963 & 4.21 & 1.23 & 1.68 & 2.1\end{array}$



10. 246
0.918
1.12
2.862
3.31
1.22
2.12
1.98

TABLE 2

Inter and intraspecific variability of growth parameters in juveniles of various crab species in estuaries along the Nigerian coastline: $b_{i}$ instantaneous allometric factor $b$ : general allometric factor, $b$ : mean allometric factor, $k$ : mean ponderal index

\begin{tabular}{|c|c|c|c|c|c|c|c|c|c|}
\hline Species & $B_{i l}$ & $B_{i 2}$ & $B_{i 3}$ & $B_{i 4}$ & $b$ & $b$ & $S D$ & $K$ & $S D$ \\
\hline Uca tangeri & 2.68 & 2.89 & 3.12 & 3.08 & 3.06 & 2.94 & 0.52 & 6.21 & 0.18 \\
\hline Sesarma elgans & 2.83 & 2.56 & 3.61 & 3.12 & 3.15 & 3.03 & 0.40 & 4.66 & 0.18 \\
\hline Sesarma huzardi & 2.32 & 2.91 & 3.01 & 3.09 & 3.28 & 2.88 & 0.32 & 8.12 & 0.12 \\
\hline Sesarma alberti_ & 2.63 & 2.98 & 3.11 & 2.68 & 2.86 & 2.85 & 0.18 & 6.04 & 1.14 \\
\hline Goniopsis pelii_ & 3.82 & 3.16 & 2.98 & 3.07 & 2.98 & 2.65 & 0.81 & 7.76 & 0.26 \\
\hline Pachygrapsus gracilis_ & 3.18 & 2.42 & 2.98 & 3.86 & 3.01 & 3.03 & 0.30 & 8.81 & 0.02 \\
\hline Metagrapsus curvatus & 3.06 & 3.19 & & & 3.25 & 2.13 & 0.42 & 12.11 & 1.18 \\
\hline Cardisoma amartum & 3.17 & 2.79 & 2.89 & 2.78 & 2.99 & 2.88 & 0.29 & 7.4 & 0.19 \\
\hline Achaeus powelli_ & 2.68 & 4.16 & 2.59 & 2.36 & 3.15 & 2.92 & 0.18 & 6.41 & 1.14 \\
\hline Ocypode cursor & 3.10 & 2.89 & 3.12 & 2.45 & 2.65 & 2.84 & 0.51 & 8.26 & 0.92 \\
\hline
\end{tabular}

The values obtained for these allometric factors lead to a mean value of $b=2.83 \pm 0.31$.

The results of weight-carapace width relationship in crab juveniles associated with the BonnyImo River mangal ecosystem is presented in Table 3. The general allometric factor displayed the following range:

TABLE 3

Interspecific variability of growth parameters in juvenile crabs associated with Bonny-Imo river mangrove swamps (S. Nigeria), $r$ : correlation coefficient $b$ : general allometric factor, $k$ : mean ponderal index

\begin{tabular}{|c|c|c|c|c|c|}
\hline Species & $R$ & $A\left({ }^{\prime} 10^{-2}\right)$ & $b$ & $k$ & $S D$ \\
\hline Callinecctes gladiator & -0.985 & 0.51 & 3.228 & 3.59 & 0.07 \\
\hline Pachygrapsus transversus & 0.969 & 0.35 & 3.121 & 2.86 & 0.05 \\
\hline Eurynome aspera_ & 0.905 & 3.54 & 2.798 & 23.9 & 11.43 \\
\hline Sesarma alberti_ & 0.993 & 1.26 & 2.950 & 10.65 & 1.45 \\
\hline Percon planissimum_ & 0.982 & 1.86 & 2.934 & 22.18 & 0.88 \\
\hline Brachynotus dentatus_ & 0.988 & 1.89 & 3.426 & 15.61 & 1.28 \\
\hline Brachynotus lucasi & 0.886 & 0.34 & 4.311 & 2.96 & 0.22 \\
\hline Dromia nodosa & 0.995 & 2.64 & 3.112 & 18.82 & 2.88 \\
\hline Heterographsus elongatus_ & 0.989 & 1.28 & 2.754 & 10.16 & 0.56 \\
\hline Grapsus grapsus_ & -0.954 & 1.39 & 3.021 & 2.54 & 1.25 \\
\hline Heterographsus erythraeus & 0.966 & 2.42 & 2.727 & 32.18 & 1.86 \\
\hline
\end{tabular}

(Adapted form Ewaoboho 1998).

\section{Brachynotus dentatus}

2754 Heterograpsus elongatus $\leq \mathrm{b} \leq 4.31$

Values obtained led to a mean value of $\mathrm{b}=3.05 \pm 0.38$. The correlation between $\mathrm{a}$ and $\mathrm{b}$ was examined (e.g. Sesarma alberti: $\mathrm{a}=-0.0126 \mathrm{~b}+0.0296(r=-0.968)$, Heterocirapsus elongates: $\mathrm{a}=-0.158 \mathrm{~b}+0.681(r=-0.998)$. Mean values obtained for the allometric factor $\mathrm{b}$ were approximately equal to 3 , which is the theoretical value often used in ichthyological studies. The specific values always differ from 3 probably due to difference in the sampling technique and 
also the scale of observation. The variability in $b$ depicts the differences in morphological characteristic and not allometric growth as such. Although the theoretical value $b=3$ is assumed to make calculation easier, it is usually better to employ the specific value within specific species.

The ponderal index, calculated with the assumed valued of $b=3$ (given in Tables 2 and 3) showed wide range of variation, making comparison and biological interpre-tation of value difficult. (e.g. the following ranges were observed $2.54 \pm 1.25$ (Grapsus grapsus) $\leq \mathrm{K} \leq 32.18 \pm$ 1.86, (Hetero-grapsus erythraeus), with a mean value of $\mathrm{K}=12.62 \pm 5.78$; and 4.66 (Sesarna elegans) $\leq \mathrm{k} \leq 18.51 \pm 4.21$ (Panoneus africanus) with a value of $\mathrm{K}=8.62 \pm 4.28$.

\section{Discussion}

The mean values of $b$ and $k$ obtained in the present investigation were $b=2.69 \pm 0.326$ and $k=$ $12.1 \pm 9.86$, which accounted for $25.6 \%$ (minimal) and $74.4 \%$ (maximal) of the variability in $b$ and for $17.8 \%$ and $82.18 \%$ of the variability in $\mathrm{k}$. This variability might have been caused by the methods of measurement or seasonal fluctuations as reflected in weight change after one year, or variability in sampling procedures. The present results were compared with that adapted from Ewa-oboho (1988), yielding the following mean values: $\mathrm{b}=2.82 \pm 0.16 ; \mathrm{k}=12.81 \pm 9.62$. The mean allometric factor deduced from the adapted data of Ewa-oboho (1988) which reflected a large number of crabs was within the range of variation for crab juveniles in the present investigation, though there was a significant difference between the two mean ponderal indices.

The numerical values of $\mathrm{k}$ are not so important, since $\mathrm{k}$ is closely correlated with $\mathrm{b}$ (Safran, 1992). For applied ichthyological studies, only b seems important and a key parameter in the weight relationship (Safran 1992). The exponent $b$ in the weight carapace-width relationship of crab juveniles was generally different from 3 and a much wider range was observed, as shown in this investigation. This calls, therefore, for careful subjection of assumptions concerning the values of $b$ to scrutiny when analyzing the growth of crabs based on models that involve this parameter.

Co-linearity or near co-linearity can be used to explain the strong correlation between a and $b$, whereby in the plot of $\log \mathrm{W} v s \log \mathrm{L}$ diagram - a slight variation in the estimated slope for the group of points leads to a strong variation closely correlated with the line origin co-ordinate (Fig. 1). In the case like this, the equation should be re-written with new non-correlated parameters, obtained by principal component analysis performed on the two (or more) correlated parameters (Safran, 1992). No obvious relation has been revealed using stomach content index (Marr, 1955). This ratio did not provide any new information which could not be obtained from the plot of original variates; the curvelinearity makes it impossible to compute variance and compare lines. The application of original variates with appropriate transformation for regression analysis will not prevent the use of data involving allometric growth.

The characteristic behaviour of $b$ could be explained by fractal geometry, which attempts to search for order in the inextricable morphology of living beings. Every living matter strives to manage a biomass, which is a volume, by means of fluxes via surfaces. Such biomass management does have dimensional constraints as growth occurs without any change of form, surface areas increase less rapidly than the volumes. For surfaces to grow at the same rate as volume, a certain highly-folded morphology, which is reminiscent of fractal objects, has to be developed (Mandelbrot, 1984; Frontier, 1987). Though fractal geometry has seldom been applied to this kind of biological problem to date, it seems to offer high perspectives. Presently, and as in this study, many working hypotheses and questions are proposed than results.

The mathematical formula $\mathrm{W}=\mathrm{KL}^{3}$ only describes the form of a crab and the ratio of its volume of a cube (where $\mathrm{L}$ is the carapace-width) length of the cube side and $\mathrm{L}^{3}$ is the volume of the cube when the crab only occupies a part of this cube. This description is only valid for each 
length and for each individual but $\mathrm{k}$ varies when the length varies since the proportion of the cube occupied by the minimal varies with the animal's age. Thus, the allometry and the relationship $\mathrm{W}$ and $\mathrm{L}^{\mathrm{b}}(\mathrm{b}=3)$ describe the growth without having a fractal geometry.

The metabolic activities necessary to sustain the life of a crab of volume $\mathrm{V}$ is proportional to $\mathrm{V}$ (although this reasoning presumes the basal metabolism for an adult whereas growth metabolism is higher relative to volume. This metabolism (flux of energy) should be proportional to the exchange surfaces, both those between organism and milieu, and those between organs, tissues, etc. within the organism. This fact points at the necessity for living things to generate a fractal geometry. If a living volume is multiplied by $\mathrm{K}^{3}$ the surfaces should be multiplied by this factor and not $\mathrm{K}^{2}$, because they should increase not like $\mathrm{L}^{2}$ but like $\left(\mathrm{L}^{32}\right)^{2}$ as, for example, the fractal dimension of an "arborescence" (equal to 3/2; Mandelbrot, 1984; Frontier, 1987). Suppose that the fractal dimension of those surfaces is constant for, (e.g. 2.5 power between 2 and 3 describing an "Occupation degree in the three-dimensional space" by the "more than surface").

If the extent of this interface is really proportional to the volume, this volume should increase more slowly than $\mathrm{L}^{3}$. As a matter of fact, if $\mathrm{V}$ is proportional to $\mathrm{L}^{\mathrm{D}}$, then $\mathrm{V}$ would be proportional to $\mathrm{S}$ and $\mathrm{L}^{\mathrm{D}}$, thus, for example

\section{Fractal "exchange surface" Allometry}

$$
\mathrm{S} \propto \mathrm{L}^{2.5} \quad \Leftrightarrow \mathrm{V} \propto 2.5
$$

b is, thus, a "mean" fractal dimension or "global equivalent" of the exchange surfaces for the metabolism of an individual. This hypothesis, which has earlier been advanced by Safran (1992) for juvenile fish species, is supported by Balon's $(1984 ; 1986)$ theory of salutatory ontogeny. It is important that any interpretation of relative growth data should take into consideration the following (Marr, 1955).

(a) data may be representative of phenotypes rather than genotypes (Martin, 1949; Taning, 1952).

(b) length, which is commonly used as a measure of size, represents only one dimension, and may, therefore, not be the best measure of size.

(c) different growth stanzas may appear in the various life-history stages.

The phenotype, Balon (1986) states, "recreated from an unspecialized single cell and is an information gathering to the genotype". A differentiated multicellular embryo or reproducing adult, unlike a single cleaving cell, is in a more equilibrium state of existence. The entire ontogeny must consist of a sequence of stabilized states. In a stabilized condition (state) cells and tissues differentiate and organs grow at various rates, as if accumulated and formed in preparation for the next, perhaps, more specialized state. The system, by all means, resists destabilization as long as possible, enabling analyzing structures to be formed and functions progress without interfering in stabilized life activities. When the system is ready for new or additional integrative actions, a shift is rapidly made - through a highly unstable interval - into the next more stable state of ontogeny. By the forested, ontogeny is, therefore, a sequence of longer stabilized states and rapid changes in integrative actions (Alberch, 1980; Adolph, 1982; Balon, 1984; 1986).

According to the theory of saltatory ontogeny (Balon, 1984; 1986) development does not proceed as a continuous accumula-tion of incon-spicuous, small changes but, instead, is a sequence of rapid changes in form and function alternating with prolonged intervals (steady states) of slower development, during which complex structures are prepared for the next rapid change. These periods of rapid change from one equilibrium state to the next are called thresholds and represent decisive events in an organism's life history. 
The hierarchical life history model of embryo, larva, juvenile, adult and senescence periods, each separated by a decisive threshold, is a consequence of the theory of saltatory ontogeny. In the fractal theory, organisms often display patchiness in space, which may be a fractal if patches are hierarchically nested. (Frontier, 1937). This model helps in recognition and interpretation of shifts in thresholds, which often results in new life history patterns (Hall, 1984). An organism passes through thresholds at much accelerated rates in order to achieve the relative security of the next stabilized state (Safran, 1992).

When the size range of individual samples is small, and when the small size range is essentially the same for all samples that are to be compared, the allometric factor (b) can be used to determine the specificity of the thresholds. For example, in Fig. 4, the two groups described might represent two different thresholds where changes (in morphology, physiology, etc.) were not obvious when using only the weight-length relationship (Fig. 4a) but could be identified when using stomach-content analysis (Fig. 4b). The diet of crabs in group A were composed of fish larvae, zoe larvae, fish egg, algae debris and detrital matter. Crabs were sampled in the rainy months of May-July, while group B crabs were sampled during the dry periods of OctoberDecember with a dietary composition of mostly pieces of exoskeleton, possibly from other crustaceans, algae debris and copepods.

The diet change between the two thresholds could be a result of growth. The allometric factor (b), therefore, plays a vital role in the determination of threshold specificity when the theories of saltatory ontogeny and fractal geometry are applied.

\section{Acknoledgement}

I. Ewa-oboho is grateful to N. J. Abby-kalio, for providing the facilities and the enthusiasm during his MPhil. degree programme in the University of Science and Technology, Port Harcourt, Nigeria. Thanks are due to Prof. George Warner of Reading University, U.K. for several field trips to Bonny Mangrove swamp for crab fauna sampling programme during his stay in Nigeria. Thanks also go to the late Powell for crab identification. The work was carried out in partial fulfillment for the award of an MPhil. degree in Marine Biology.

\section{References}

Abby-kalio N. J. and Warner G. F. (1984). Effects of two different feeding regimes on the Chela closer muscles of the shore crab Carcinus macnas (L.). Mar. Behav. Physiol 11: 209-218.

Adolph E. F. (1982). Physiologca! integration in action physiologist. Wash. 25 (Suppl.) V. 167.

Alberch P. (1980). Ontogenesis and morphological diversification. Am. Zool. 20: 653-667.

Balon E. K. (1984). Reflections on some decisive events in the early life of fishes. Trans. Am. Fish. Soc. 113 (2): 178185.

Bauchot R. and Bauchot M. L. (1978). Coefficient de condition et indice poderal chez les Teleosteens. Cybium 3(4): $3-16$.

Cott H. B. (1929). Observations on the natural history of racing crab Ocypode ceratophtha Lina from Beira. Proc. Zool. Soc. London 4: 755-765.

Davidson R. J. and Marsden I. D. (1987). Size relationship and relative growth in New Zealand swimming crab Ovalipes catharus (white) J. Crust. Biol. 7: 308-317.

Ewa-oboho I. (1988). Effects of simulated crude oil spill on Mangrove swamp crabs of Bonny Estuary S. Nigeria. (MPhil. Thesis.) University of Science \& Technology, Port Harcourt, Nigeria 256 pp.

Ewa-oboho I. (1993). Substratum preference of the tropical estuarine crabs, Ucatangeri Eydoux (Ocypodidae) and (Ocypode) cursor (L.) Ocypodidae Hydrobiologia 271: 119-127.

Frontier S. (1987). Applications of fractal theory to ecology. In Development in numerical ecology. (P. Legendre and L. Legendre, ed.) NATO ASI Ser. (G: EcoI. Sciences) 14: 335-378.

Fulton T. W. (1911). The sovereignty of the sea. Edinburgh, London.

Hall B. K. (1934). Developmental processes underlying heterochrony as an evolutionary mechanism Can. J. Zool. 62: $1-7$.

Hyslop (1980). Stomach content analysis a review of methods and their applications. J. Fish Biol. 17: 411-429.

Huxley J. S. (1932). Problem of relative growth, pp. 1-276. Methuen, London.

Hartnoll R. G. (1978). The determination of relative growth in Crustacea. Crutaceana 34: 281-293. 
Le Cren E. D. (1951). Length-weight relationship and seasonal cycle in gonad weight and condition in the Perch (Perca fluviatilis). J. Anim. Ecol. 20: 201-219.

Lee S. Y. (1992). Ecological implications of cheliped size in crabs: Data from Carcinus maenas and Liocarcinus holsatus. Mar. Ecol. Prog. Ser. 84: 151-160.

Mandelbrot B. (1984). Les objects fractals: forme, chance et dimension. Flammarion, Paris.

Marr J. C. (1955). The use of morphometric data in systematic, racial and relative growth studies in fishes. Copeia 1: 23-31.

Martin W. R. (1949). The mechanics of environmental control of body form in fishes. Univ. Toronto Stud. Biol. Ser. 58: $1-19$.

Ricker W. E. (1980). Calcul et interpretation des statistiques biologiques des populations de poisons. Bull. Fish. Res. Bd Can. $191 \mathrm{~F}$.

Safran P. (1992). Theoretical analysis of the weight-length relationship in fish juveniles Mar. Biol. 112: 545-551.

Taning A. V. (1952). Experimental study of meristic characters in fishes. Biol. Rev. Cambridge Philos. Soc. 27 (2): 169-193.

Weatherley A. H. (1972). Growth and ecology of fish populations. Academic Press, London. 